Article

\title{
Sustainable Agriculture: Stable Robust Control in Presence of Uncertainties for Multi-Functional Indoor Transportation of Farm Products
}

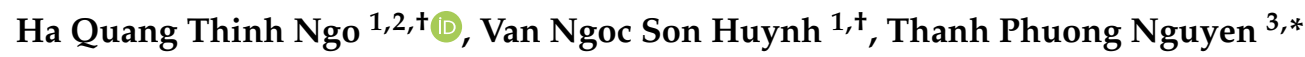 \\ and Hung Nguyen ${ }^{3}$ \\ 1 Department of Mechatronics, Faculty of Mechanical Engineering, Ho Chi Minh City University of \\ Technology (HCMUT), 268 Ly Thuong Kiet Street, District 10, Ho Chi Minh City 700000, Vietnam; \\ nhqthinh@hcmut.edu.vn (H.Q.T.N.); 1870060@hcmut.edu.vn (V.N.S.H.) \\ 2 Vietnam National University, Ho Chi Minh City, Linh Trung Ward, Thu Duc District, \\ Ho Chi Minh City 700000, Vietnam \\ 3 HUTECH Institute of Engineering, Ho Chi Minh City University of Technology (HUTECH), \\ Ho Chi Minh City 700000, Vietnam; n.hung@hutech.edu.vn \\ * Correspondence: nt.phuong@hutech.edu.vn \\ + These authors contributed equally to this work.
}

Received: 28 August 2020; Accepted: 26 October 2020; Published: 4 November 2020

\begin{abstract}
Currently, integrated trends play a key role in every aspect of automation applications. In particular, if the mechanization of agriculture becomes a competitive factor among farmers or nations, then the multi-functional transportation of agricultural products is inevitable in global trade. In sustainable transportation, the challenge of overcoming stable control in harsh environments, such as through imprecise parameters or varying loads, should be addressed. In this paper, a novel controller for a nonholonomic mechanical system able to adapt to uncertainties is proposed. Based on the multi-functional autonomous carrier (MAC), the system configuration of the kinematic and dynamic model is launched in order to identify the unstable problems that arise when tracking the trajectory. To solve these troubles, the decoupled formation of a MAC system has been investigated by considering two second-order components, namely a linear speed-based sub-system and angular speed-based sub-system. To stabilize the whole system using the Lyapunov theory, the advanced control techniques are studied. To validate the proposed approach, a series of test scenarios have been carried out. From the superior performance of numerous trials, it is clear that our approach is effective, feasible, and reasonable for the advanced control of agricultural applications.
\end{abstract}

Keywords: agricultural applications; multi-functional platform; nonlinear control; motion control

\section{Introduction}

Recent research efforts in mobile carriers have been devoted to the appearance of novel concept systems that allow vehicles to handle different missions with or without human supervision. One of the challenges in farming automation is the ability to perceive and adapt to uncertain factors existing in the farmhouse. Knowledge of advanced control strategies can be beneficial for autonomous carriers in order to deal with their environment more efficiently and to better support precise farming work. Moreover, developments in commerce and global trade are accelerating through technology. The revolution of agricultural robotics, which brings countless benefits, is currently occurring in every nation $[1,2]$. The perception of a mechanical carrier in agricultural transportation is not unfamiliar anymore. To achieve success in global competition, the optimization and automation of logistics processes is a way in which the efficiency of resource use in the environment of a distribution center 
can be improved. The latest progress in the field of autonomous carriages, in combination with loading and unloading, enables integrating the trends of various technologies into one hardware [3]. The results that have already been obtained within this field were reinforced by specific demands from local distributors, and the lack of proper control techniques for stable motion was the main reason for focusing further on this work.

Automation in precision agriculture is not only concerned with the application of unmanned aerial vehicles [4] but also with the wide range of advantages of grounded vehicles [5,6]. In various studies, in order to assist farmers, many issues have been considered, such as dynamic characteristics and the identification of autonomous vehicle models in agriculture [7], prototype design for seed selectors [8], search-based approaches for vehicle scheduling [9], and the development of a positioning mechanism for unmanned farming vehicles [10]. In the scope of the management of an agricultural warehouse or distribution center, our main focus is placed on analyzing the models of the autonomous carriers, developing a globally asymptotically robust control scheme, and examining the proposed design in practical scenarios. This paper provides a detailed implementation of the above features.

\section{Materials and Methods}

Adaptation when confronted with uncertainty was originally a key issue for researchers, as it can affect the control process. Generally, design controllers in previous works can be briefly summarized into two groups, namely kinematic-based models and kinematic-dynamic-based models. For the first category, this method focuses on establishing a motion controller for an autonomous robot via the angular velocity and linear velocity. As a result, the kinematic model is utilized to compute the tracking system errors. In detail, investigators $[11,12]$ used the adaptive control with a globally asymptotically stable kinematic model. In the case of unknown input parameters, the system information, such as the $r$ and $b$ coefficients, would have fluctuated. The authors suggested an adaptive scheme to estimate these parameters. Hence, the left and right angular velocities of the robot could be altered. In the same method, but adding to the actuator dynamic, an adaptive controller for an electrically driven nonholonomic mobile robot was investigated $[13,14]$. The simplified parameter estimation technique was recommended in order to reduce the number of tuning parameters. From the Lyapunov stability theory, all of the signals in the closed-loop system were semi-globally, uniformly, ultimately bound.

In reality, uncertain factors and disturbances always exist in external surroundings. An example of this is that a mobile robot must continuously elevate different loads during its mission. This would lead to a change in the moment inertia of the overall system. In another case, the control scheme might not be able to consider the system state or actuator information. To overcome these drawbacks, the kinematic-dynamic-based model approach is suggested to develop the motion controller. It is classified into two sub-categories, namely the sequential scheme and combining scheme. In sequential control, the hardware system employs the driving effect of linear velocity and angular velocity in order to track the reference signal. By utilizing the dynamic model, estimation of the tracking errors can be obtained based on these velocities. At this stage, various strategies are manipulated in order to evaluate the driving parameters. Pourboghrat, F. et al. $[15,16]$ developed an adaptive control based on the backstepping technique, so that the asymptotic stability converges to zero. However, these researchers did not consider the variation of the input system mass. In the approach using sliding mode control (SMC), the authors in $[17,18]$ explored the advantageous points of SMC in order to reject the external disturbances or uncertain parameters. The control scheme is embedded in a personal computer, which is not as flexible as micro-processor-based programming. Through the dynamic performance of the system, the tracking results are superior and excellent. The integration of a kinematic controller and a torque controller for a nonholonomic mobile robot is presented in $[19,20]$. Three basic navigation problems were indicated, namely tracking a reference trajectory, path following, and stabilization of a desired posture. A robust-adaptive controller, including a neural network to deal with the unmodeled bounded disturbances, and a computed-torque controller to deal with the unstructured, unmodeled dynamics in the vehicle were used. The same control structure in $[21,22]$ 
was built, but it differed in the use of the backstepping technique. The limitation of this work is that it did not consider the fluctuation of a system mass.

Furthermore, combining the schemes is an alternative method for different developers in order to simultaneously lessen the tracking performance of the errors. In fact, perfect knowledge of the system information is unattainable. To deal with this, an additional controller with a guaranteed performance should be derived-namely, an artificial intelligence-based controller [23] consisting of conventional torque-control, neural network backstepping, and perfect velocity tracking controller. A key point in this research is that the same control algorithm should work if the behavior or goal of the system is modified. In particular, a multi-layer feed-forward neural network together a with well-designed kinematic controller might enhance the performance of the mobile robot drastically. To solve the problems of the dynamic characteristics of an autonomous robot with unknown coefficients, fuzzy control is used as a substitute tool [24]. An expert-related method does not actually need any information about the system state and freely controls it. In most situations, the input control signal is often a driving moment, while the voltage signal is fed to an actuator. In [25], a solution for the input voltage signal was implemented in a detailed procedure. In most previous studies, the term "perfect velocity tracking" seems to be unrealistic. In fact, the active wheels are generalized by actuators that are driven by voltage instead of torque. Thus, the wheel actuator input voltage was chosen as the control input for the torque controller. The fuzzy logic system was utilized to estimate the nonlinear robot functions involving unknown robot parameters, while the stability and error bound were proven using the Lyapunov theory. Several research articles (summarized in Table 1) were further reviewed in order to study their insights into mobile robot control.

Table 1. Summary of the background research.

\begin{tabular}{|c|c|c|c|c|c|}
\hline Approach & Author(s) & Methodology & Advantage & Limit & tion \\
\hline \multirow[t]{2}{*}{ Kinematic-based model } & $\begin{array}{l}\text { Jia, P. et al. [11], } \\
\text { Xin, L. et al. [12] }\end{array}$ & $\begin{array}{c}\text { Adopt } \\
\text { estimations of } \\
\text { the } r \text { and } b \\
\text { values to } \\
\text { design the } \\
\text { adaptive } \\
\text { trajectory } \\
\text { controller }\end{array}$ & $\begin{array}{l}\text { Compensating the } \\
\text { parametric } \\
\text { uncertainties for the } \\
\text { sake of a better } \\
\text { tracking } \\
\text { performance }\end{array}$ & $\begin{array}{l}\text { Timing for } \\
\text { convergence is } \\
\text { not guaranteed }\end{array}$ & \multirow{2}{*}{$\begin{array}{c}\text { Focusing only } \\
\text { on the } \\
\text { kinematic } \\
\text { model and } \\
\text { discarding the } \\
\text { dynamical } \\
\text { factors causing } \\
\text { the unpractical } \\
\text { development }\end{array}$} \\
\hline & $\begin{array}{l}\text { Park, B. S. et al. [13], and } \\
\text { Haqshenas, AR. et al. [14] }\end{array}$ & $\begin{array}{l}\text { Treat all } \\
\text { uncertainties } \\
\text { and derive } \\
\text { adaptation } \\
\text { laws from the } \\
\text { Lyapunov } \\
\text { stability theory }\end{array}$ & $\begin{array}{l}\text { Consider both the } \\
\text { robot } \\
\text { kinematic-dynamic } \\
\text { and actuator states }\end{array}$ & $\begin{array}{l}\text { Requiring a lot of } \\
\text { effort to tune the } \\
\text { parameters }\end{array}$ & \\
\hline \multirow{3}{*}{$\begin{array}{c}\text { Kinematic-dynamic-based } \\
\text { model }\end{array}$} & $\begin{array}{l}\text { Pourboghrat F. et al. [15] } \\
\text { and Boukens, M. et al. [16] }\end{array}$ & $\begin{array}{l}\text { Adaptive } \\
\text { control derived } \\
\text { for mobile } \\
\text { robots using } \\
\text { the } \\
\text { backstepping } \\
\text { technique, for } \\
\text { tracking a } \\
\text { reference } \\
\text { trajectory and } \\
\text { for stabilization } \\
\text { to a fixed } \\
\text { posture }\end{array}$ & $\begin{array}{l}\text { Limit the velocity } \\
\text { and acceleration to } \\
\text { prevent the robot's } \\
\text { wheels from slipping }\end{array}$ & $\begin{array}{l}\text { Time processing } \\
\text { is sub-optimal }\end{array}$ & \multirow{3}{*}{$\begin{array}{c}\text { The total effects } \\
\text { of the } \\
\text { sequential } \\
\text { control are not } \\
\text { clear }\end{array}$} \\
\hline & $\begin{array}{l}\text { Solea R. et al. [17] and } \\
\text { Chen, H. et al. [18] }\end{array}$ & $\begin{array}{l}\text { Using } \\
\text { mathematical } \\
\text { relations } \\
\text { among signals } \\
\text { to perform the } \\
\text { proposed } \\
\text { sliding } \\
\text { controller }\end{array}$ & $\begin{array}{l}\text { Powerful } \\
\text { computation due to } \\
\text { personal computer }\end{array}$ & $\begin{array}{l}\text { The variations of } \\
\text { the parameters } \\
\text { are very small }\end{array}$ & \\
\hline & $\begin{array}{l}\text { Fierro R. et al. [19] and } \\
\text { Ibari, B. [20] }\end{array}$ & $\begin{array}{l}\text { Integrating } \\
\text { backstepping } \\
\text { kinematics into } \\
\text { dynamics }\end{array}$ & $\begin{array}{l}\text { Online neural } \\
\text { network weight } \\
\text { tuning }\end{array}$ & $\begin{array}{l}\text { The calculation is } \\
\text { time-consuming }\end{array}$ & \\
\hline
\end{tabular}


Table 1. Cont.

\begin{tabular}{|c|c|c|c|c|c|}
\hline Approach & Author(s) & Methodology & Advantage & \multicolumn{2}{|c|}{ Limitation } \\
\hline \multirow{3}{*}{$\begin{array}{l}\text { Kinematic-dynamic-based } \\
\text { model }\end{array}$} & $\begin{array}{l}\text { Shakourzadeh, S. et al. [21], } \\
\text { Ibari B. et al. [22], and } \\
\text { Fierro and Lewis [23] }\end{array}$ & $\begin{array}{c}\text { A combined } \\
\text { kinematic/torque } \\
\text { control law } \\
\text { using the } \\
\text { backstepping } \\
\text { and } \\
\text { stabilization } \\
\text { techniques }\end{array}$ & $\begin{array}{c}\text { Robust with } \\
\text { bounded disturbance } \\
\text { and does not require } \\
\text { path planning }\end{array}$ & $\begin{array}{c}\text { Complex } \\
\text { programming } \\
\text { and unattainable } \\
\text { real-time } \\
\text { performance }\end{array}$ & \multirow{3}{*}{$\begin{array}{c}\text { Although } \\
\text { powerful tools } \\
\text { and advanced } \\
\text { model-based } \\
\text { analysis are } \\
\text { discussed, } \\
\text { burden } \\
\text { computation } \\
\text { and timing cost } \\
\text { are } \\
\text { unavoidable }\end{array}$} \\
\hline & Foudil A. et al. [24] & $\begin{array}{c}\text { A new } \\
\text { approach based } \\
\text { on the fuzzy } \\
\text { concept using } \\
\text { the optimized } \\
\text { IF-THEN rule } \\
\text { based on an } \\
\text { evolutionary } \\
\text { algorithm }\end{array}$ & $\begin{array}{l}\text { Avoid any collision } \\
\text { in a complex } \\
\text { environment }\end{array}$ & $\begin{array}{l}\text { Lack of active } \\
\text { control toward } \\
\text { unforeseeable } \\
\text { scenarios }\end{array}$ & \\
\hline & Tamoghna D. et al. [25] & $\begin{array}{l}\text { The system } \\
\text { uncertainty, } \\
\text { parameter } \\
\text { variation, and } \\
\text { unknown } \\
\text { nonlinearities } \\
\text { are estimated } \\
\text { using a fuzzy } \\
\text { logic system }\end{array}$ & $\begin{array}{l}\text { More realistic than } \\
\text { most torque } \\
\text { controllers }\end{array}$ & $\begin{array}{c}\text { General form of } \\
\text { math expression } \\
\text { and incompliance } \\
\text { of initial } \\
\text { conditions may } \\
\text { be impractical }\end{array}$ & \\
\hline
\end{tabular}

From the above discussions, it can be seen easily that the sequential control in a kinematic-dynamic-based model approach is effective and less complicated than the combining control. In recent works, most researchers selected the center point of the autonomous robot to coincide with the middle point between two driving wheels. In some real situations, this would be inappropriate, owing to the inequivalent distribution of the load. In addition, the nonholonomic system-based model is considered as the fundamental theory for different feedback controllers in tracking the trajectory. The nonlinear feedback controllers could be explored through mathematical expressions. Nevertheless, these controllers might be too multifaceted to be embedded into a real platform. For several situations, the integrated trend among numerous schemes or the upgraded traditional control algorithm would be encountered.

In recent years, the wide range of applications for factory automation have caused an increasing number of studies on autonomous transportation. There are plenty of mobile robots that are capable of handling dissimilar tasks in a warehouse-for instance, a tractor-trailer using a feedback linearizing dynamic controller [26], automatic visual guidance for a forklift vehicle [27,28], enhanced control strategy for a mobile robot [29,30], and upper limits of forces for a freight-car truck [31]. Each of these is available for a specified working area. In the scope of this application, the autonomous transportation of medium- and small-size freights is demonstrated. In Figure 1, the topological map is potentially utilized to describe the environment map, as shown. The grid-based map is characterized by five parts, namely manual sorting space, operation center, charging space, driving line, and parking space. The role of each part is quite diverse. A worker accomplishes his mission for pickup and delivery in the manual sorting space. Then, carriers track the planning route from the start point to the target point in the driving line. The server computer and central control room are positioned in the operation center. When the power of a carrier is less, the battery needs to be replenished in the charging space. All of the carriers are collected in the parking space before the system is turned on. 


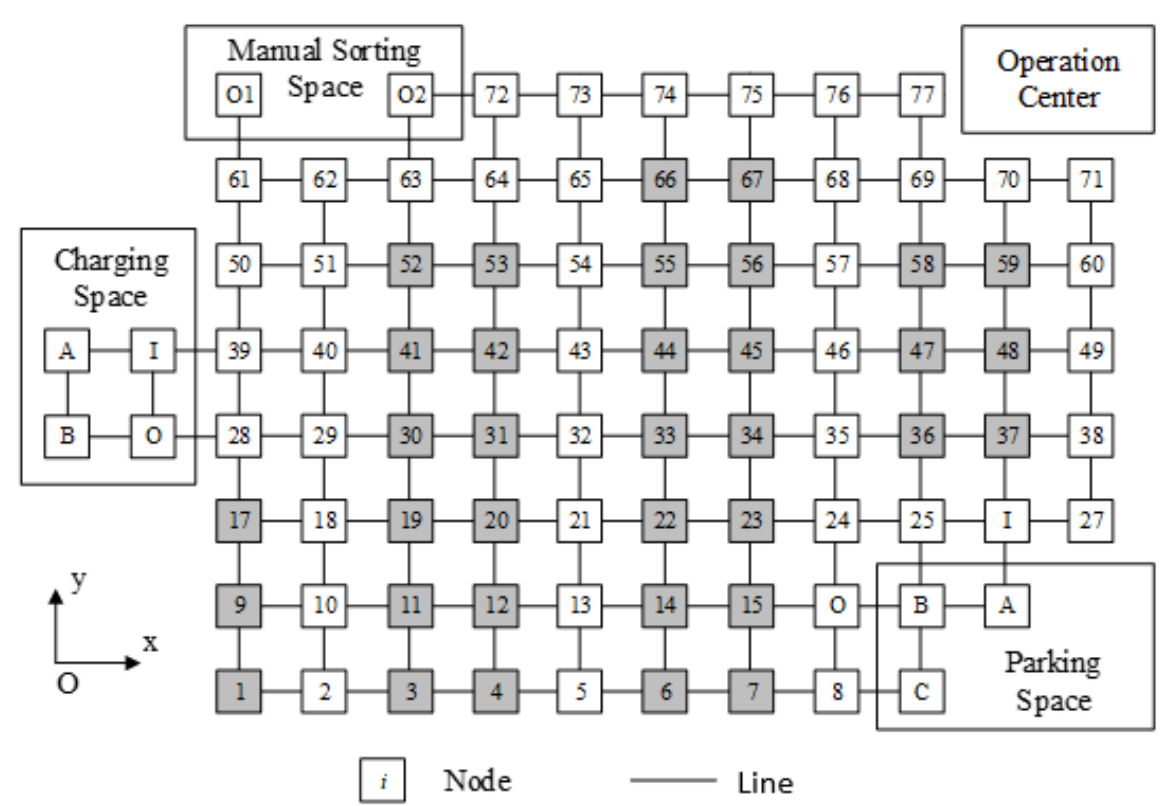

Figure 1. Typical grid-based working map.

A newer platform [32] to transport cargo is explained in Figure 2. This hardware has more advantages, namely a compact size, flexibility, and multi-functions. It can carry materials in both the loading and unloading process via vertical and horizontal manipulation. In the vertical handling mode, the robot elevates materials on its back. Otherwise, it brings things on a trailer. In any case, the robot and cargo become a rigid body. Hereafter, the unknown loads could cause difficulties in robot control. Additionally, uncertain parameters always exist in a practical model. There is a need to develop a motion controller for the multi-function autonomous robot in order to adapt to uncertainties in the storehouse or distribution center.

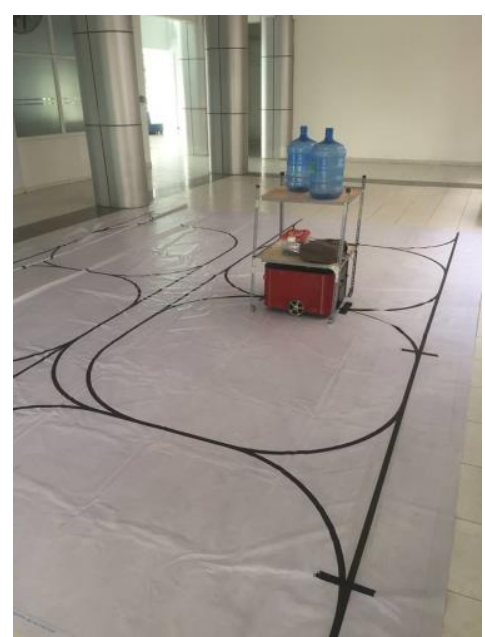

(a)

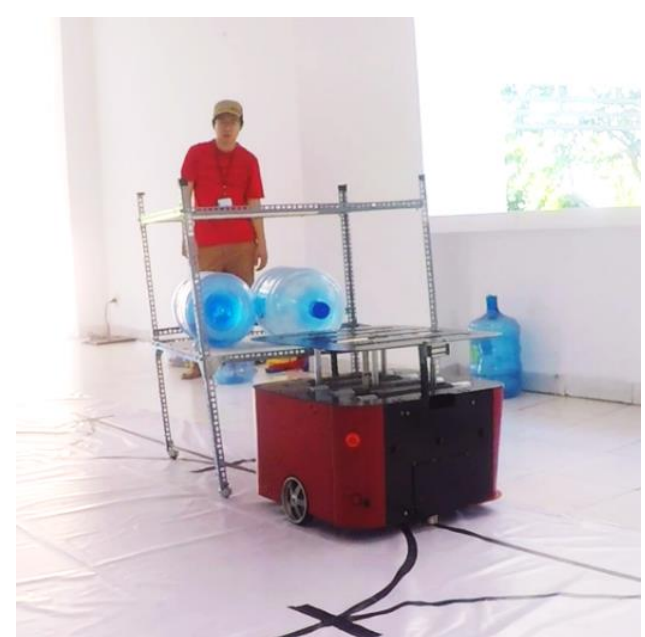

(b)

Figure 2. Novel platform of multi-function robot prototype [33]: lifting-type (a), tractor-trailer (b).

\section{Results}

The initial physical architecture of the autonomous carrier is characterized in Figure 3. It consists of four wheels: two side driving wheels, one front passive wheel, and one rear passive one. There are some conventions-for example, the grounded carrier only moves on a two-dimensional flat map, the distribution of freight is uniformly weighted, and the central point of the carrier and origin of 
$\mathrm{xOy}$ are the same. Table 2 summarizes whole mathematical symbols in this section. Consider that the reference trajectory in reference coordinate and speed of autonomous carrier are $q_{P}^{T}=\left[\begin{array}{lll}x_{P} & y_{P} & \theta\end{array}\right]$ and $\vartheta^{T}=\left[\begin{array}{ll}v & \omega\end{array}\right]$, correspondingly. Consequently, the relationship between linear speed and angular speed is expressed as

$$
\dot{q}_{P}=S\left(q_{P}\right) \vartheta=\left[\begin{array}{cc}
\cos \theta & 0 \\
\sin \theta & 0 \\
0 & 1
\end{array}\right]\left[\begin{array}{c}
v \\
\omega
\end{array}\right]
$$

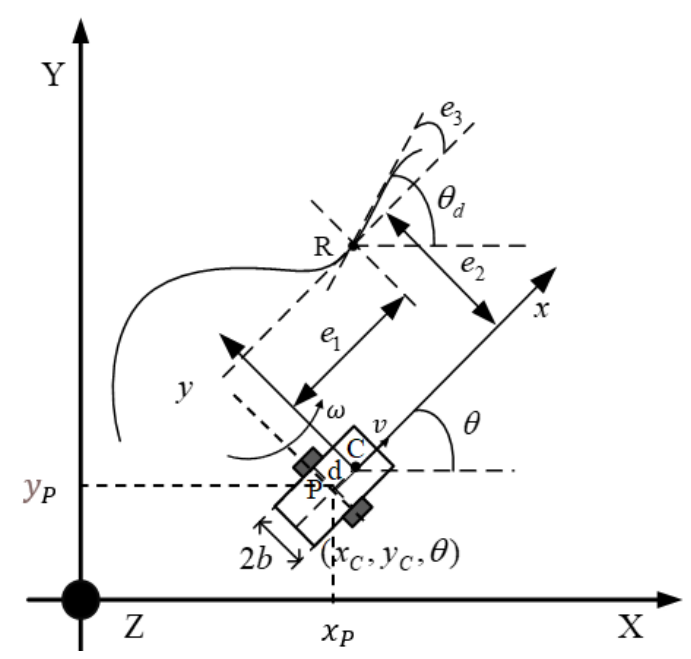

Figure 3. Physical parameters of kinematic configuration in autonomous carrier.

Table 2. List of mathematical symbols.

\begin{tabular}{cc}
\hline Notation & Description \\
\hline $2 b$ & Distance between two active driving wheels \\
$2 r$ & Diameter of active driving wheel \\
$\theta$ & Heading angle between $O x$ and actual OX \\
$\theta_{r}$ & Reference angle between $O x$ and desired OX \\
$\mathrm{d}$ & Distance between C point and P point \\
$\lambda$ & Lagrange constraint \\
$J$ & Inertial moment \\
$m$ & Weight of autonomous system \\
$F\left(\dot{q}_{C}\right)$ & Friction force between carrier and floor \\
$V_{m}\left(q_{C}, \dot{q}_{C}\right)$ & Coriolis matrix \\
$G\left(q_{C}\right)$ & Gravity force vector \\
$M\left(q_{C}\right)$ & Symmetric and positive-definite inertia matrix \\
$A\left(q_{C}\right)$ & System constraints matrix \\
$B\left(q_{c}\right)$ & Bounded external disturbance \\
$\tau_{d}$ & Driving torque of two active wheels, $\tau^{T}=\left[\begin{array}{ll}\tau_{1} & \tau_{2}\end{array}\right]$ \\
$\tau_{1}, \tau_{2}$ &
\end{tabular}

From Equation (1), the reference coordinate of the center point is determined.

$$
\dot{q}_{C}=S\left(q_{C}\right) \vartheta=\left[\begin{array}{cc}
\cos \theta & -d \sin \theta \\
\sin \theta & d \cos \theta \\
0 & 1
\end{array}\right]\left[\begin{array}{l}
v \\
\omega
\end{array}\right]
$$


Using the Lagrange approach, the dynamic characteristics, including the kinetic and potential energy, are illustrated [7].

$$
M\left(q_{C}\right) \ddot{q}_{C}+V_{m}\left(q_{C}, \dot{q}_{C}\right) \dot{q}+F\left(\dot{q}_{C}\right)+G\left(q_{C}\right)+\tau_{d}=B\left(q_{C}\right) \tau-A^{T}\left(q_{C}\right) \lambda
$$

The boundedness of $\tau_{d}$ ensures that the uncertainty factor is not too large and it is appropriate for taking into account the limitations of the physical hardware. The system parameters are chosen as follows:

$$
\begin{gathered}
M\left(q_{C}\right)=\left[\begin{array}{ccc}
m & 0 & m d \sin \theta \\
0 & m & -m d \cos \theta \\
m d \sin \theta & -m d \cos \theta & J
\end{array}\right] B\left(q_{C}\right)=\frac{1}{r}\left[\begin{array}{cc}
\cos \theta & \cos \theta \\
\sin \theta & \sin \theta \\
b & -b
\end{array}\right] \\
A^{T}\left(q_{C}\right)=\left[\begin{array}{c}
-\sin \theta \\
\cos \theta \\
-d
\end{array}\right] G\left(q_{C}\right)=0 V_{m}\left(q_{C}, \dot{q}_{C}\right)=\left[\begin{array}{ccc}
0 & 0 & m d \dot{\theta} \cos \theta \\
0 & 0 & m d \dot{\theta} \sin \theta \\
0 & 0 & 0
\end{array}\right]
\end{gathered}
$$

Without loss of generality, the above parameters are simplified as

$$
M=M\left(q_{C}\right), A=A\left(q_{C}\right), B=B\left(q_{c}\right), V=V_{m}\left(q_{C}, \dot{q}_{C}\right), S=S\left(q_{C}\right)
$$

Taking a derivative of (2), then substituting into (3) and multiplying with $S^{T}(q)$, we have

$$
S^{T} \cdot M \cdot(S \dot{\vartheta}+\dot{S} \vartheta)+S^{T} \cdot V \cdot S \cdot \vartheta+S^{T} F+S^{T} \tau_{d}=S^{T} B \tau-S^{T} A^{T} \lambda
$$

Thus, we obtain

$$
S^{T} \cdot A^{T}=0
$$

Hypothesis 1 (H1). The autonomous carrier moves in three-dimensional space with generalized coordinate $q_{C}^{T}=\left[\begin{array}{lll}x_{C} & y_{C} & \theta\end{array}\right]$ and without slipping phenomenon.

$$
A\left(q_{C}\right) \dot{q}_{C}=\dot{x}_{C} \sin \theta-\dot{y}_{C} \cos \theta-d \dot{\theta}=0
$$

The driving wheels are designed to ensure that they are in touch with the floor at any time. Thanks to this assumption, the controller could drive the system efficiently.

Hypothesis 2 (H2). The external disturbance is unknown but bounded.

$$
\left|\tau_{d}\right| \leq \partial
$$

With

$$
\begin{gathered}
\bar{M}=S^{T} \cdot M \cdot S=\left[\begin{array}{cc}
m & 0 \\
0 & \bar{J}
\end{array}\right], \bar{J}=J-m d^{2}, J>m d^{2} \\
\bar{B}=S^{T} \cdot B=\frac{1}{r}\left[\begin{array}{ll}
1 & -1 \\
b & -b
\end{array}\right], \bar{V}=S^{T}(M . \dot{S}+V \cdot S)=\left[\begin{array}{ll}
0 & 0 \\
0 & 0
\end{array}\right], d(t)=-S^{T}\left(F+\tau_{d}+M . \dot{S}\right)
\end{gathered}
$$

From (6) and (7), the dynamical equation becomes the following:

$$
\bar{M} \dot{\vartheta}=\bar{B} \tau+d(t)
$$


Forces which act on the system are derived from (12):

$$
\left\{\begin{array}{l}
\bar{J} \dot{\omega}=u_{1}+d_{1}(t) \\
m \dot{v}=u_{2}+d_{2}(t)
\end{array}\right.
$$

where $u=\left[\begin{array}{l}u_{1} \\ u_{2}\end{array}\right]=\frac{1}{r}\left[\begin{array}{c}\tau_{1}-\tau_{2} \\ b \tau_{1}+b \tau_{2}\end{array}\right], d(t)=\left[\begin{array}{l}d_{1}(t) \\ d_{2}(t)\end{array}\right]$

$d_{i}(t), i=1,2$ denotes factors of external disturbances and uncertainties;

$u_{i}(t), i=1,2$ means the control signal of two active wheels.

$$
\dot{q}_{C}=\left[\begin{array}{c}
\dot{x}_{C} \\
\dot{y}_{C} \\
\dot{\theta}
\end{array}\right]=\left[\begin{array}{c}
v \cos \theta-d \omega \sin \theta \\
v \sin \theta+d \omega \cos \theta \\
\omega
\end{array}\right]
$$

The purpose of the control scheme is to solve the tracking trajectory problem. In order to tend to zero in finite time, the reference path is defined as

$$
\dot{q}_{R}=\left[\begin{array}{c}
\dot{x}_{R} \\
\dot{y}_{R} \\
\dot{\theta}_{R}
\end{array}\right]=\left[\begin{array}{c}
v_{R} \cos \theta_{R} \\
v_{R} \sin \theta_{R} \\
\omega_{R}
\end{array}\right]
$$

where $\left[x_{R}(t), y_{R}(t), \theta_{R}(t)\right]^{T} \in \mathfrak{R}^{3}$ is the reference coordinate and $\left[v_{R}(t), \omega_{R}(t)\right]^{T} \in \mathfrak{R}^{2}$ is the reference signals of linear speed and angular speed, respectively. The tracking error of system is identified as

$$
e=\left[\begin{array}{l}
e_{x} \\
e_{y} \\
e_{\theta}
\end{array}\right]=T\left(q_{C}\right)\left(q_{R}-q_{C}\right)=\left[\begin{array}{ccc}
\cos \theta & \sin \theta & 0 \\
-\sin \theta & \cos \theta & 0 \\
0 & 0 & 1
\end{array}\right]\left[\begin{array}{c}
x_{R}-x_{C} \\
y_{R}-y_{C} \\
\theta_{R}-\theta_{C}
\end{array}\right]
$$

As a result,

$$
\lim _{t \rightarrow \infty}\left\|q_{R}-q_{C}\right\|=0 \Rightarrow \lim _{t \rightarrow \infty} e=0, \text { and } T\left(q_{C}\right) \text { is bounded }
$$

In the real world, several constraints related to hardware or physical phenomena still arise in the system. To meet these requirements, some theories are indicated as below.

Hypothesis 3 (H3). The lower and upper limits of linear speed and angular speed exist correspondingly.

$$
\begin{gathered}
\omega_{R}^{\text {lower }} \leq\left|\omega_{R}\right| \leq \omega_{R}^{\text {upper }} \\
\left|\dot{\omega}_{R}\right| \leq \dot{\omega}_{R}^{\text {upper }} \\
\left|v_{R}\right| \leq v_{R}^{\text {upper }} \\
\left|\dot{v}_{R}\right| \leq \dot{v}_{R}^{\text {upper }}
\end{gathered}
$$

Obviously, the upper and lower values of linear speed help to maintain stable motion while the boundary values of angular speed could assist in avoiding collapse when it turns at a corner.

Hypothesis 4 (H4). Although the external disturbances or uncertain signals are unknown, it is always bounded by a positive value so that $\left|d_{i}(t)\right| \leq D$. 
Although the uncertain mass of cargo is unknown, however, the agricultural products are delivered in one package with max weight. Hence, it is reasonable to estimate the max value of total cargo. Later, the design of a dynamic controller is essential to secure that the system errors of Equation (14) tend to zero and are stable in finite time.

$$
\left\{\begin{array}{c}
v_{f} \\
\omega_{f}
\end{array}=\begin{array}{c}
v_{R} \cos e_{\theta}+k_{1} e_{x} \\
k_{2} e_{y} v_{R}+\omega_{R}+k_{3} \sin e_{\theta}
\end{array}\right.
$$

where $k_{1}, k_{2}, k_{3}>0$ are constant

$v_{f}, \omega_{f}$ : linear velocity and angular velocity of a dynamic controller and

$$
\frac{d}{d t}\left[\begin{array}{c}
e_{x} \\
e_{y} \\
e_{\theta}
\end{array}\right]=v\left[\begin{array}{c}
-1 \\
0 \\
0
\end{array}\right]+\omega\left[\begin{array}{c}
e_{y} \\
-e_{x} \\
-1
\end{array}\right]+\left[\begin{array}{c}
v_{R} \cos e_{\theta} \\
v_{R} \sin e_{\theta} \\
\omega_{R}
\end{array}\right]
$$

Lyapunov function $V_{0}$ is selected as

$$
V_{0}=\frac{1}{2}\left(e_{x}^{2}+e_{y}^{2}\right)+\frac{1-\cos e_{\theta}}{k_{2}}
$$

Then, deriving (24) in the time domain and substituting (23) into the below result,

$$
\dot{V}_{0}=e_{x} \dot{e}_{x}+e_{y} \dot{e}_{y}+\frac{1}{k_{2}} \sin e_{\theta} \dot{e}_{\theta}=-k_{1} e_{x}^{2}-\frac{k_{3}}{k_{2}} \sin ^{2} e_{\theta} \leq 0
$$

In the theory of Lyapunov, it is concluded that the controller in (22) can guarantee the stability of the system in (16) and the tracking errors converge to zero in definite time.

Merging (13) and (22) into the below equations,

$$
\left\{\begin{array}{cc}
v_{f} & v_{R} \cos e_{\theta}+k_{1} e_{x} \\
\omega_{f} \\
\bar{J} \dot{\omega} \\
m \dot{v} & k_{2} v_{R} e_{y}+\omega_{R}+k_{3} \sin e_{\theta} \\
u_{1}+d_{1}(t) \\
u_{2}+d_{2}(t)
\end{array}\right.
$$

At this stage, linear speed and angular speed play a role as target control when combined with the dynamic model. The speed errors are computed as $e_{v}=v-v_{f}$ and $e_{\omega}=\omega-\omega_{f}$.

Far ahead, Equation (26) is transformed:

$$
\left\{\begin{array}{cc}
e_{v} & v-v_{R} \cos e_{\theta}-k_{1} e_{x} \\
e_{\omega} \\
\bar{J} \dot{\omega}
\end{array}=\omega-k_{2} v_{R} e_{y}-\omega_{R}-k_{3} \sin e_{\theta}\right.
$$

To lessen the burden of computation, Equation (27) might be divided into two sub-systems:

$$
\begin{gathered}
\left\{\begin{array}{c}
e_{\omega} \\
\bar{J} \dot{\omega}
\end{array}=\begin{array}{cc}
\omega-k_{2} v_{R} e_{y}-\omega_{R}-k_{3} \sin e_{\theta} \\
u_{1}+d_{1}(t)
\end{array}\right. \\
\left\{\begin{array}{c}
e_{v} \\
m \dot{v}
\end{array}=\begin{array}{cc}
v-v_{R} \cos e_{\theta}-k_{1} e_{x} \\
u_{2}+d_{2}(t)
\end{array}\right.
\end{gathered}
$$


For the second-order system in (28), the sliding surface is established as

$$
s_{1}=e_{\omega}+\int_{0}^{t}\left(k_{4} e_{\omega}+k_{5}\left|e_{\omega}\right|^{p} \operatorname{sign}\left(e_{\omega}\right)\right) d t
$$

where $1<p<2, k_{4}, k_{5}>0$ is constant.

Taking the first derivative of Equation (30) and replacing the speed errors into below expression,

$$
\begin{aligned}
& \dot{s}_{1}=\dot{e}_{\omega}+k_{4} e_{\omega}+k_{5}\left|e_{\omega}\right|^{p} \operatorname{sign}\left(e_{\omega}\right) \\
& =\dot{\omega}-\dot{\omega}_{f}+k_{4} e_{\omega}+k_{5}\left|e_{\omega}\right|^{p} \operatorname{sign}\left(e_{\omega}\right) \\
& =\frac{u_{1}}{\bar{J}}-\dot{\omega}_{f}+k_{4} e_{\omega}+k_{5}\left|e_{\omega}\right|^{p} \operatorname{sign}\left(e_{\omega}\right)
\end{aligned}
$$

To maintain the state variables on a sliding surface, it must be satisfied $\dot{s}=0$; at that time, the equivalent controller is derived from (31).

$$
u_{e q 1}=-\bar{J}\left[-\dot{\omega}_{f}+k_{4} e_{\omega}+k_{5}\left|e_{\omega}\right|^{p} \operatorname{sign}\left(e_{\omega}\right)\right]
$$

In this case, the disturbance is rejected when the system state is on a sliding surface. Otherwise, the design controller must be able to adapt with the existing uncertainties. At this moment, the proposed controller can be rewritten as

$$
u_{\text {asw } 1}=-\bar{J}\left[\sigma_{1} s_{1}+\hat{\eta}_{1}\left|s_{1}\right|^{q} \operatorname{sign}\left(s_{1}\right)\right]
$$

where $0<q<1$ and $\sigma_{1}>0$ are conversion coefficients

$\hat{\eta}_{1}>0$ is the estimation value of $\eta_{1}, \eta_{1} \geq D\left|\frac{1}{s_{1}}\right|^{q}$

$\widetilde{\eta}_{1}=\hat{\eta}_{1}-\eta_{1}$ is the error of the estimation value $\hat{\eta}_{1}$

The update value for $\hat{\eta}_{1}$ is calculated as

$$
\dot{\hat{\eta}}_{1}=\mu_{1}\left|s_{1}\right|^{q+1}
$$

where $\mu_{1}>0$ is tuning coefficient

Totally, the motion controller for autonomous carrier is

$$
u_{1}=u_{e q 1}+u_{a s w 1}=-\bar{J}\left[-\dot{\omega}_{f}+k_{4} e_{\omega}+k_{5}\left|e_{\omega}\right|^{p} \operatorname{sign}\left(e_{\omega}\right)+\sigma_{1} s_{1}+\hat{\eta}_{1}\left|s_{1}\right|^{q} \operatorname{sign}\left(s_{1}\right)\right]
$$

The chosen Lyapunov function is illustrated as

$$
V_{1}=\frac{1}{2} \bar{J}_{1}^{2}+\frac{1}{2 \mu_{1}} \widetilde{\eta}_{1}^{2}
$$

Moreover, taking the first derivative of Equation (36), we obtain

$$
\begin{gathered}
\dot{V}_{1}=\bar{J} s_{1} \dot{s}_{1}+\frac{1}{\mu_{1}}\left(\hat{\eta}_{1}-\eta_{1}\right) \dot{\eta}_{1} \\
=\bar{J} s_{1}\left(\frac{u_{1}+d_{1}(t)}{\bar{J}}-\dot{\omega}_{f}+k_{4} e_{\omega}+k_{5}\left|e_{\omega}\right|^{p} \operatorname{sign}\left(e_{\omega}\right)\right)+\frac{1}{\mu_{1}}\left(\hat{\eta}_{1}-\eta_{1}\right) \dot{\hat{\eta}}_{1} \\
=-\bar{J} \sigma_{1} s_{1}^{2}-\bar{J} \hat{\eta}_{1}\left|s_{1}\right|^{q+1}+s_{1} d_{1}(t)+\left(\hat{\eta}_{1}-\eta_{1}\right)\left|s_{1}\right|^{q+1} \\
\leq-\bar{J} \sigma_{1} s_{1}^{2}-\bar{J} \hat{\eta}_{1}\left|s_{1}\right|^{q+1}+\left|s_{1}\right| D+\left(\hat{\eta}_{1}-\eta_{1}\right)\left|s_{1}\right|^{q+1} \\
\leq-\bar{J} \sigma_{1} s_{1}^{2}-\left|s_{1}\right|^{q+1}(\bar{J}-1) \hat{\eta}_{1}
\end{gathered}
$$

with $D \leq \eta_{1}\left|s_{1}\right|^{q}$.

By tuning $\bar{J}$ so that $\bar{J}-1 \geq 0$, then $\dot{V}_{1} \leq 0$. As a result, the stability of the proposed controller (35) by the Lyapunov theory. As well, the second-order system (28) is stabilized by controller (35) with adaptive rule (34). 
On the other hand, to certify that the error of speeds in (22) tends to zero in finite time, an integral terminal sliding mode surface for the second-order system (29) is built:

$$
s_{2}=e_{v}+\int_{0}^{t}\left(k_{4} e_{v}+k_{5}\left|e_{v}\right|^{p} \operatorname{sign}\left(e_{v}\right)\right) d t
$$

with conditions $1<p<2$

$k_{1}, k_{2}>0$ are constants.

Under the expression of derivative math, Equation (38) becomes

$$
\begin{aligned}
& \dot{s}_{2}=\dot{e}_{v}+k_{4} e_{v}+k_{5}\left|e_{v}\right|^{p} \operatorname{sign}\left(e_{v}\right) \\
& =\dot{v}-\dot{v}_{f}+k_{4} e_{v}+k_{5}\left|e_{v}\right|^{p} \operatorname{sign}\left(e_{v}\right)
\end{aligned}
$$

The motion controller for the second-order system (29) is proposed as

$$
u_{2}=u_{e q 2}+u_{\mathrm{asw} 2}=-m\left[-\dot{v}_{f}+k_{4} e_{v}+k_{5}\left|e_{v}\right|^{p} \operatorname{sign}\left(e_{v}\right)+\sigma_{2} s_{2}+\hat{\eta}_{2}\left|s_{2}\right|^{q} \operatorname{sign}\left(s_{2}\right)\right]
$$

including $0<q<1, \sigma_{2}>0$ : conversion coefficients $\hat{\eta}_{2}>0$ is the estimation value of $\eta_{2}, \eta_{2} \geq D\left|\frac{1}{s_{2}}\right|^{q}$ placing $\widetilde{\eta}_{2}=\hat{\eta}_{2}-\eta_{2}$ as the error of the estimation value $\hat{\eta}_{2}$

The update value for $\hat{\eta}_{2}$ is calculated as

$$
\dot{\hat{\eta}}_{2}=\mu_{2}\left|s_{2}\right|^{q+1}
$$

where $\mu_{2}>0$ is the tuning coefficient.

The Lyapunov candidate function is performed as

$$
V_{2}=\frac{1}{2} m s_{2}^{2}+\frac{1}{2 \mu_{2}} \widetilde{\eta}_{2}^{2}
$$

and

$$
\begin{gathered}
\dot{V}_{2}=m s_{2} \dot{s}_{2}+\frac{1}{\mu_{2}}\left(\hat{\eta}_{2}-\eta_{2}\right) \dot{\hat{\eta}}_{2} \\
=m s_{2}\left(\frac{u_{2}+d_{2}(t)}{m}-\dot{v}_{f}+k_{4} e_{v}+k_{5}\left|e_{v}\right|^{p} \operatorname{sign}\left(e_{v}\right)\right)+\frac{1}{\mu_{2}}\left(\hat{\eta}_{2}-\eta_{2}\right) \dot{\hat{\eta}}_{2} \\
=-m \sigma_{2} s_{2}^{2}-m \hat{\eta}_{2}\left|s_{2}\right|^{q+1}+s_{2} d_{2}(t)+\left(\hat{\eta}_{2}-\eta_{2}\right)\left|s_{2}\right|^{q+1} \\
\leq-m \sigma_{2} s_{2}^{2}-m \hat{\eta}_{2}\left|s_{2}\right|^{q+1}+\left|s_{2}\right| D+\left(\hat{\eta}_{2}-\eta_{2}\right)\left|s_{2}\right|^{q+1} \\
\leq-m \sigma_{2} s_{2}^{2}-\left|s_{2}\right|^{q+1}(m-1) \hat{\eta}_{2}
\end{gathered}
$$

where $D \leq \eta_{2}\left|s_{2}\right|^{q}$

By tuning $m$ so that $m-1 \geq 0$, then $\dot{V}_{2} \leq 0$. Accordingly, in the sense of Lyapunov theory, the stability of the proposed controller (40) is confirmed. In addition, the second-order system (29) is stabilized by controller (40) with adaptive rule (41).

\section{Discussions}

In this section, our purpose is to confirm the suitability and effectiveness of the proposed approach. Moreover, the improved performance of this system could be revealed by means of different kinds of reference paths. Specifically, a circular path and line path are introduced as reference tracking trajectories, as shown in Figure 4. Using the physical dimensions and capability, Table 3 shows the initial setup values. For convenient simulation, the external disturbances are estimated as $d_{1}=0.3 \dot{v}+0.2 v+\omega+\cos t \cdot e^{-t}$ and $d_{2}=0.28 \dot{\omega}+v+0.3 \omega+\sin t$. The primary reference position of nonholonomic carrier is $q_{R}=\left(x_{R}(0), y_{R}(0), \theta_{R}(0)\right)=(2,1,0.25 \pi)$ while it starts at $q_{C}=\left(x_{C}(0), y_{C}(0), \theta(0)\right)=(3,0,0.4)$. The reference signals of angular speed and linear speed are $v_{R}=3 \mathrm{~m} / \mathrm{s}, \omega_{R}=1.5 \mathrm{rad} / \mathrm{s}$ correspondingly. 


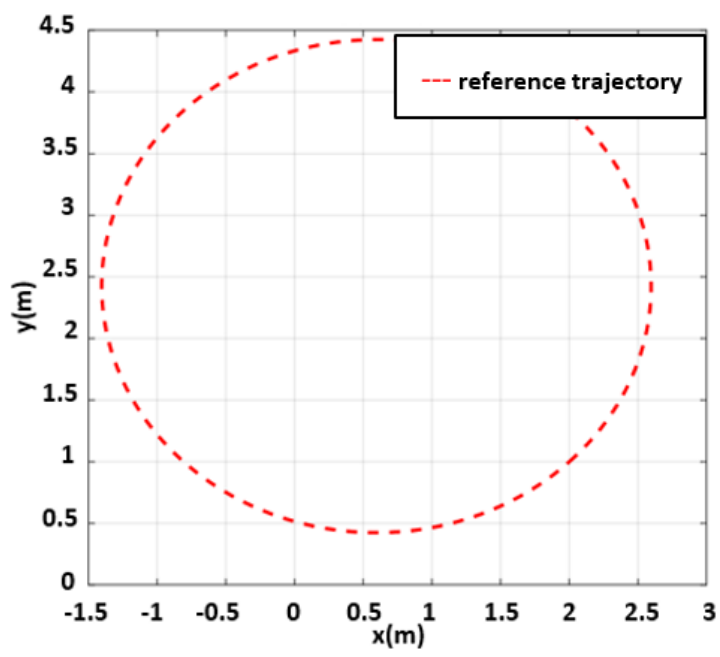

(a)

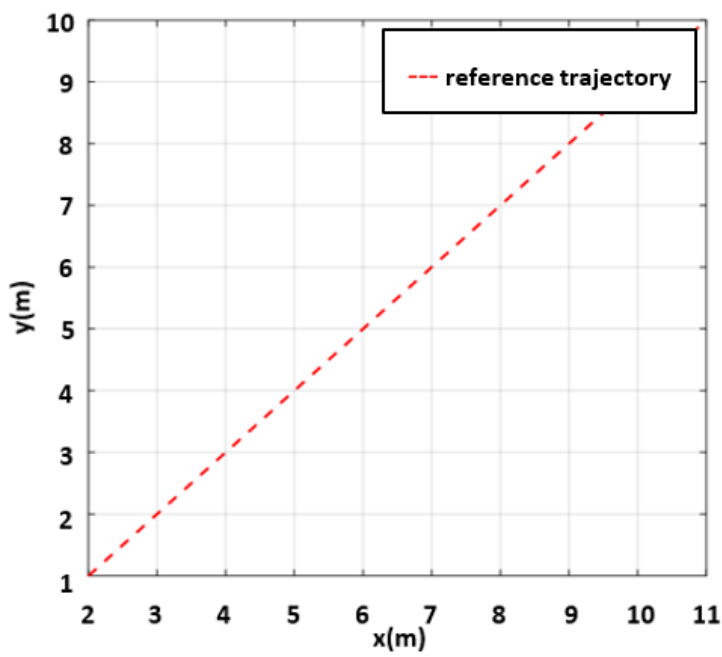

(b)

Figure 4. Reference trajectory for both circular curve (a) and linear curve (b).

Table 3. Initial values of system configuration.

\begin{tabular}{ccc}
\hline Parameter & Value & Unit \\
\hline Length & 700 & $\mathrm{~mm}$ \\
Width & 650 & $\mathrm{~mm}$ \\
Height & 400 & $\mathrm{~mm}$ \\
Weight & 23 & $\mathrm{~kg}$ \\
Max loading & 50 & $\mathrm{~kg}$ \\
Diameter of wheel & 250 & $\mathrm{~mm}$ \\
Distance between C point and P point & 150 & $\mathrm{~mm}$ \\
Inertial moment & 5 & $\mathrm{~kg} \cdot \mathrm{m}$ \\
Angular speed reference & 1.5 & $\mathrm{rad} / \mathrm{s}$ \\
Linear speed reference & 3 & $\mathrm{~m} / \mathrm{s}$ \\
\hline
\end{tabular}

To match with the practical scenario, a closed trajectory including different continuous segments is suggested as Figure 5. The setting control process is recalled as Table 4 that the autonomous carrier initializes at $q_{C}=\left(x_{C}(0), y_{C}(0), \theta(0)\right)=(0,0,0)$, the reference signals of angular speed and linear speed are $v_{R}=2 \mathrm{~m} / \mathrm{s}, \omega_{R}=2 \mathrm{rad} / \mathrm{s}$, respectively. At this stage, the total mass of the autonomous system consists of a carrier and load. More specifically, the outcomes of the tracking performance are presented in Figures 6 and 7. As the carrier must follow the desired path uninterruptedly, the motion controller should generate the pulse train to servo actuators. The comments from these values are that the carrier tracks less errors when it stays in a straight path, and the tracking errors peak at the corner or contiguous segment between lines. This is reasonable, as the mechanical carrier does not know the reference map in advance. 


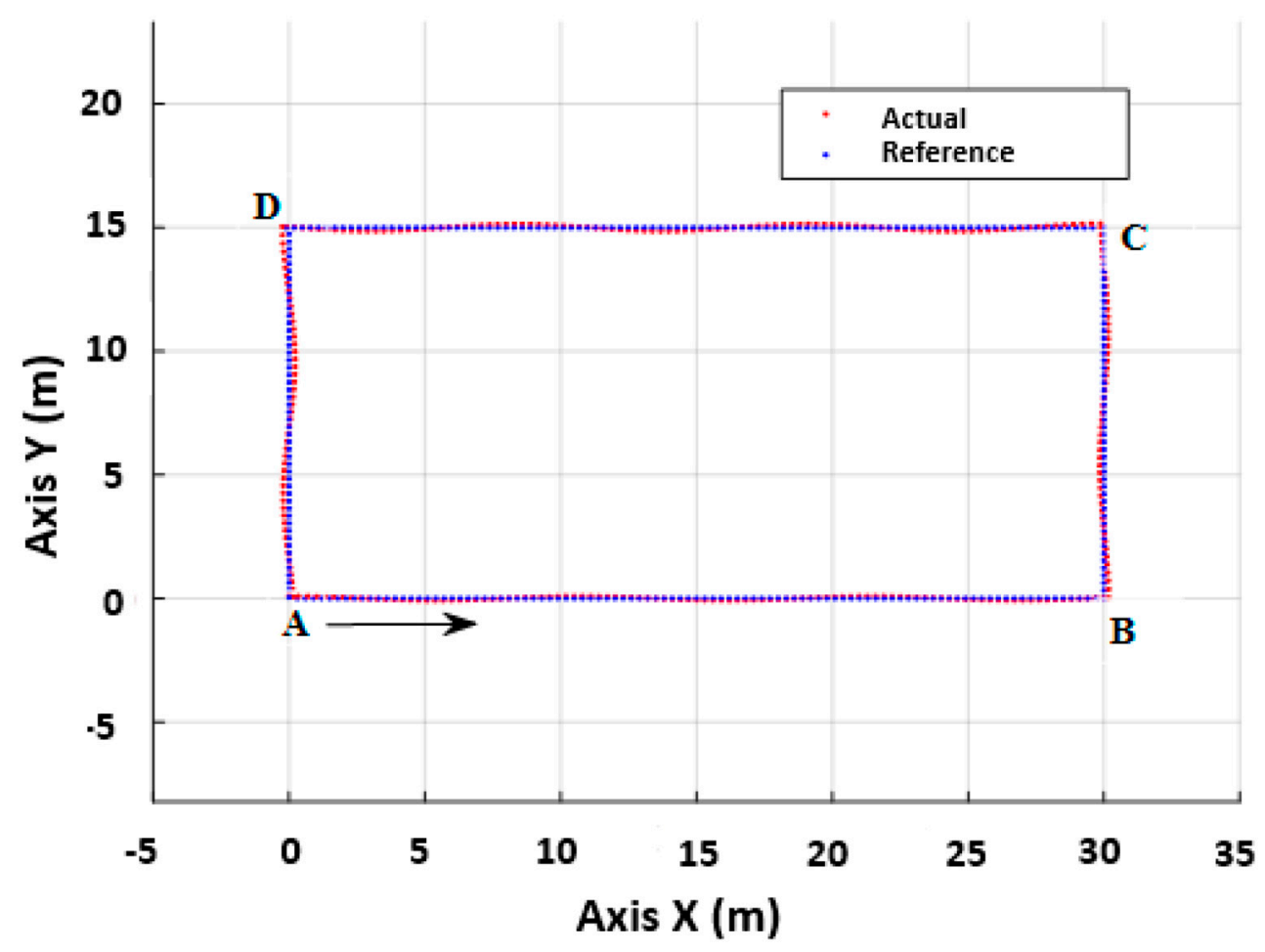

Figure 5. Tracking results of driving in working map of $x-y$ coordinate.

Table 4. Description of tuning control coefficients.

\begin{tabular}{cccc}
\hline Parameter & Value & Parameter & Value \\
\hline$p$ & 1.1 & $q$ & 0.3 \\
$\sigma_{1}$ & 7.8 & $k_{1}$ & 1 \\
$\sigma_{2}$ & 2.5 & $k_{2}$ & 15 \\
$\mu_{1}$ & 0.8 & $k_{3}$ & 20 \\
$\mu_{2}$ & 0.3 & $k_{4}$ & 0.7 \\
$\eta_{1}=\eta_{2}$ & 0 & $k_{5}$ & 0.2 \\
\hline
\end{tabular}

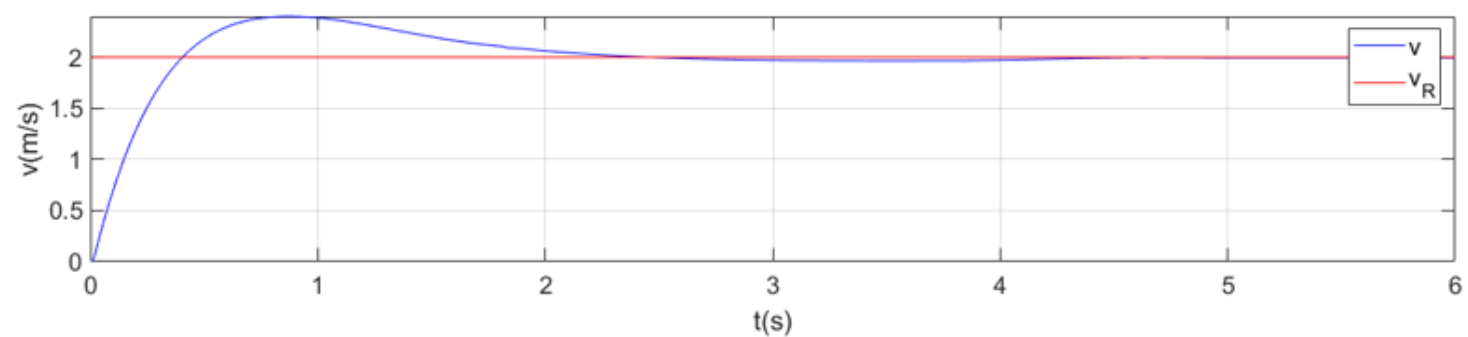

(a)

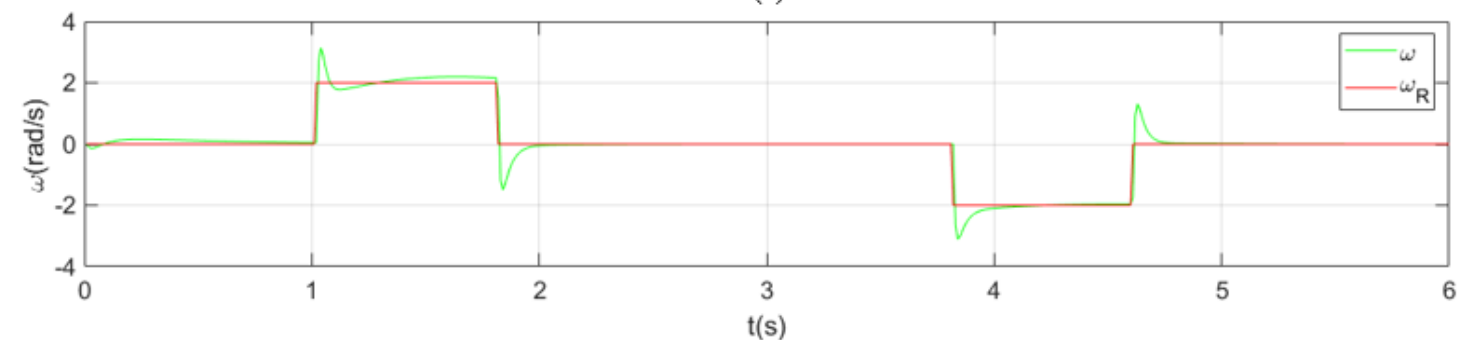

(b)

Figure 6. Driving performance (linear speed: (a) and angular speed: (b)) of proposed controller in tracking complex trajectory. 


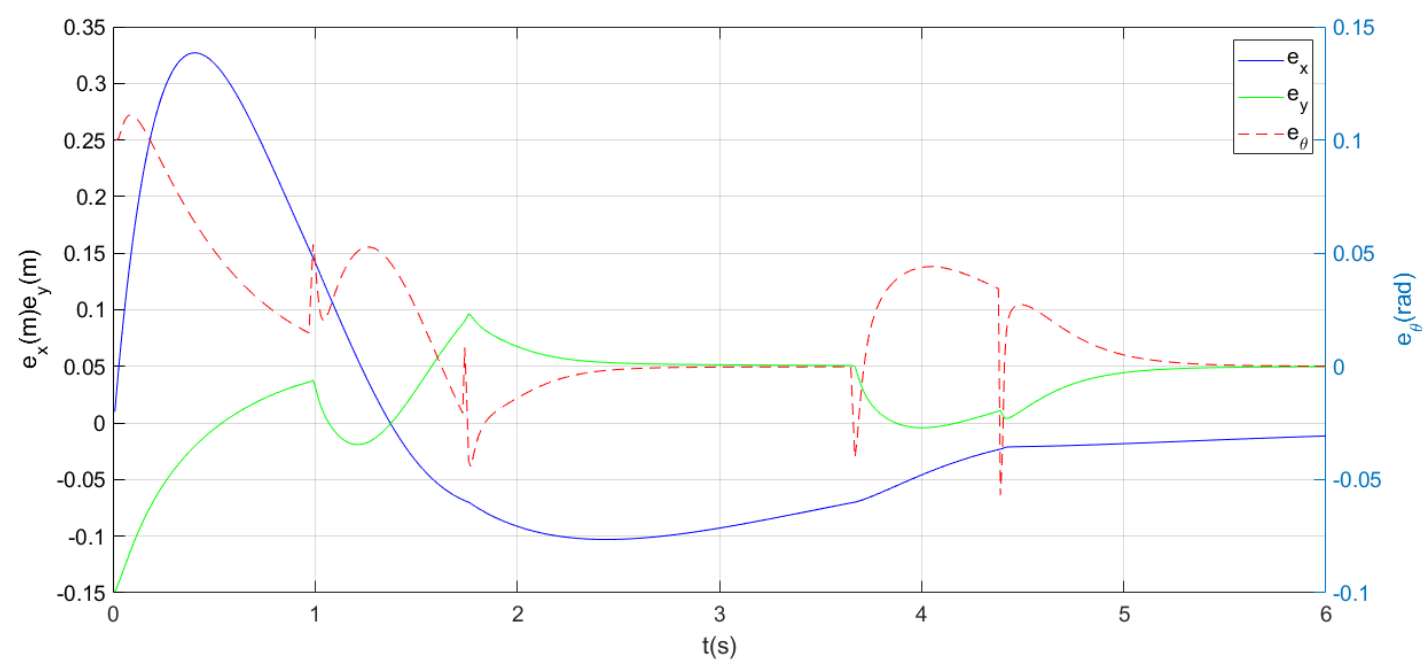

Figure 7. Driving performance (linear errors $e_{x}$ : (blue) and $e_{y}$ (green), angular error $e_{\theta}$ (red)) of proposed controller in tracking complex trajectory.

Competitive performance is a must. Our approach originates from both kinematic and dynamic models so that control rules are created. The other control algorithm in the literature [34], which is based on the adaptive nonsingular fast terminal sliding mode control (ANFTSMC) technique to drive the wheeled mobile robot, was chosen for comparison. The same conditions were equally employed in the two controllers. To visualize the advanced achievements, the entire path was segmented into sub-routes-a circle route and line route. The tracking performance of the position using ANFTSMC in both the circle and line route is illustrated in Figure 8. Intuitively, the output results suffer unexpected effects from chattering on the system signals. The actual trajectory in the circular path does not track well, while it tends to diverge in the tracking line path. For more detail, several results of the errors and velocities are demonstrated in Figure 9. In a circular trajectory, the robot seems to struggle to track the reference profile as it starts at any point in the $x / y$ plane. However, the circle curve requires the ANFTSMC controller to change the control signals continuously. Consequently, the tracking errors fluctuate slightly and are too large to drive the wheeled robot. In the linear trajectory, the control performance of the ANFTSMC scheme is not as good as its desired signal.

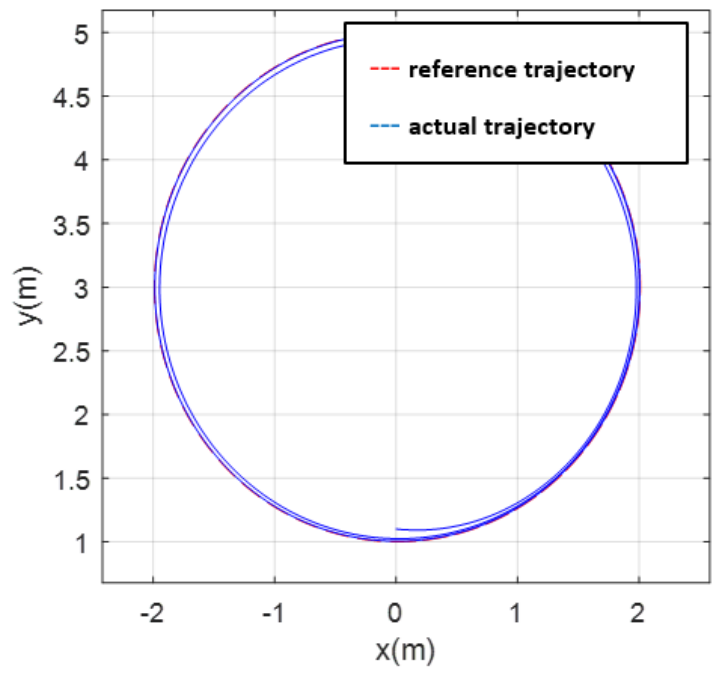

(a)

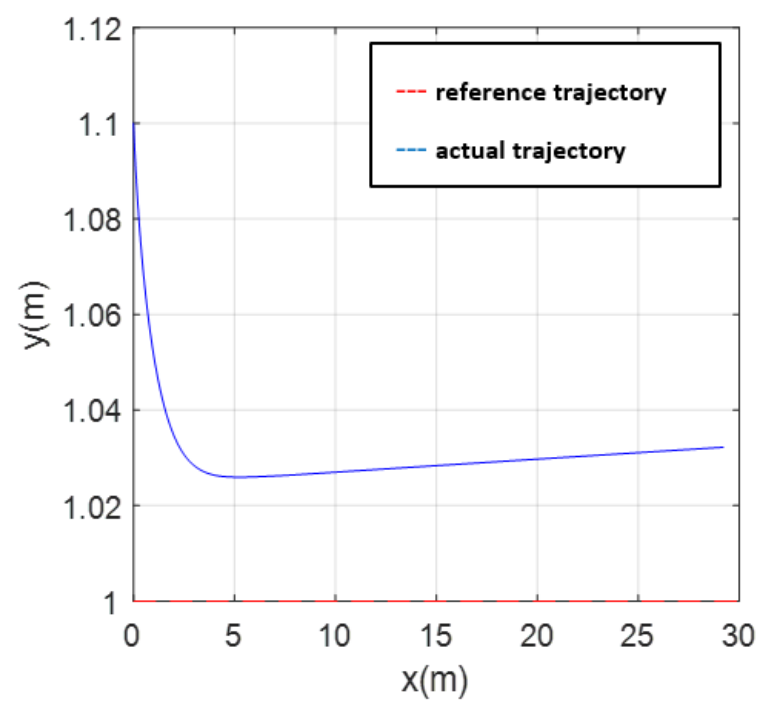

(b)

Figure 8. Laboratory results in tracking position of circle route (a) and line route (b) by ANFTSMC. 


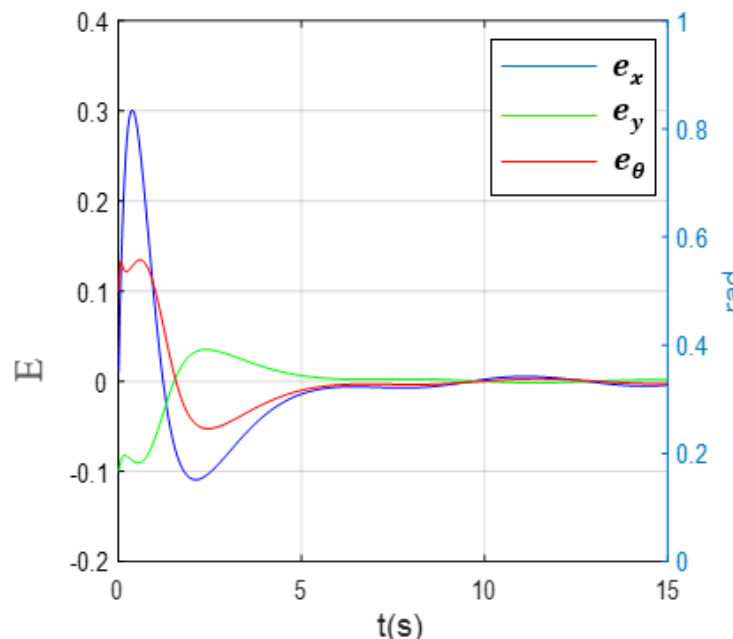

(a)
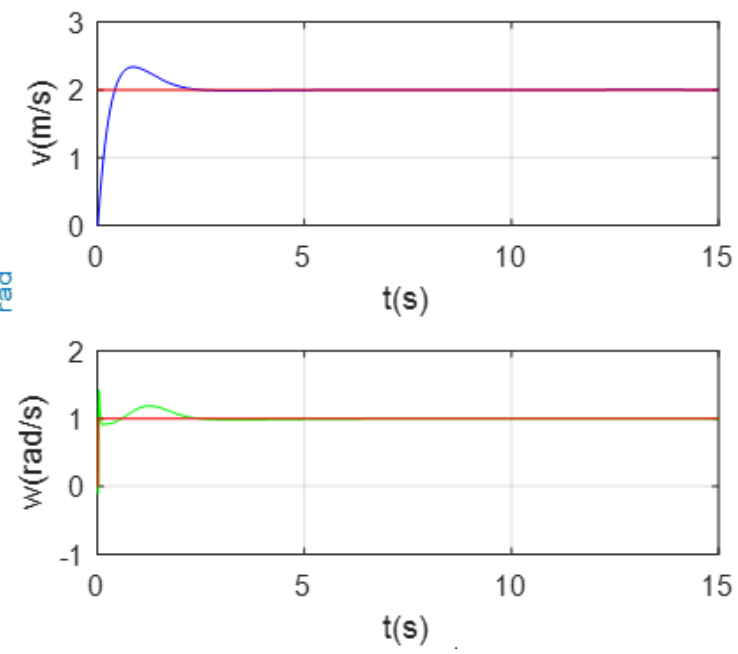

(b)

Figure 9. Laboratory results in tracking errors of circle route (a) and tracking velocities of line route (b) by ANFTSMC.

For comparative purposes, the same settings were employed in our controller. The output performance of the proposed scheme for both cases is described in Figure 10. In the case of a circular track, better performance could be achieved by our controller, while the chattering phenomenon was perfectly discarded. Accordingly, the driving actuators could receive the correct command from the motion controller. Although the line path was easier to manipulate for the whole system, the controller needed to be sensitive to changes and was able to drive the system back to reference trajectory. The driving performance of the tracking errors and velocities is depicted in Figure 11. It is obviously recognized that even though unknown uncertainties exist in the system, the proposed control strategy perfectly generates the driving command. In a short period, the velocity performance of our controller did not possess the changes suddenly and continuously. It is also important to note that the terms of tracking errors are always crucial factors for discovering a superior response. The adaptive rule might enhance our controller so as to overcome the uncertain parameters. A list of comparative statistics is synthesized in Table 5. Three tracking values are mentioned-maximum, minimum, and root-mean-square (RMS) error. As the autonomous carrier starts far from the reference trajectory, in the cases of both paths, two controllers obtained a maximum tracking error at 0.1. Later, the control commands would drive the system to tend to the reference path. In the linear segments, the ANFTSMC controller did not track well, while our controller performed with excellent results. In the curved trajectory, two control schemes produced the same tracking performance.

Table 5. Comparative results of tracking errors.

\begin{tabular}{ccccccc}
\hline \multirow{2}{*}{ Controller } & \multicolumn{3}{c}{ Linear Trajectory } & \multicolumn{3}{c}{ Circular Trajectory } \\
\cline { 2 - 7 } & Max & Min & RMS & Max & Min & RMS \\
\hline ANFTSMC & 0.1 & 0.024 & 0.027 & 0.1 & 0.0078 & 0.0096 \\
Our approach & 0.1 & 0.00075 & 0.00091 & 0.1 & 0.00042 & 0.00087 \\
\hline
\end{tabular}




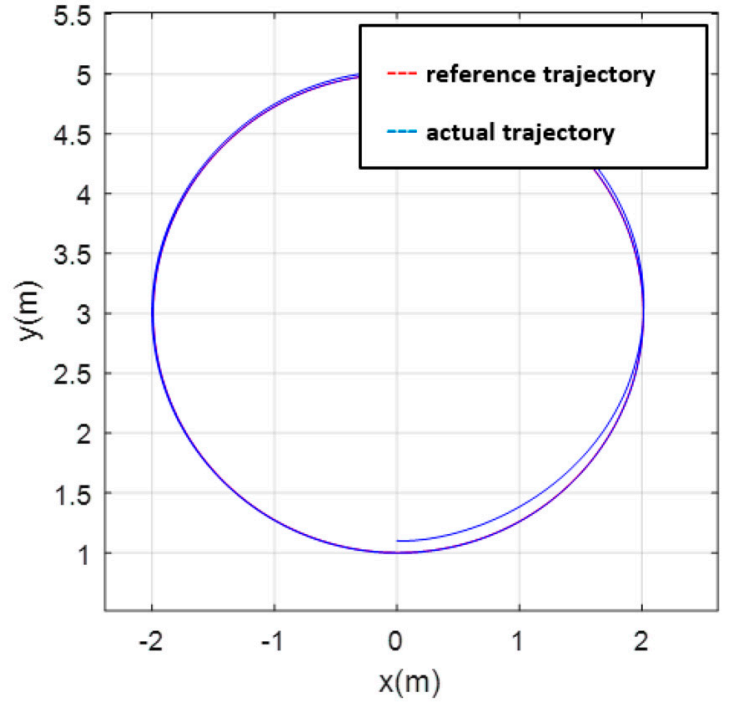

(a)

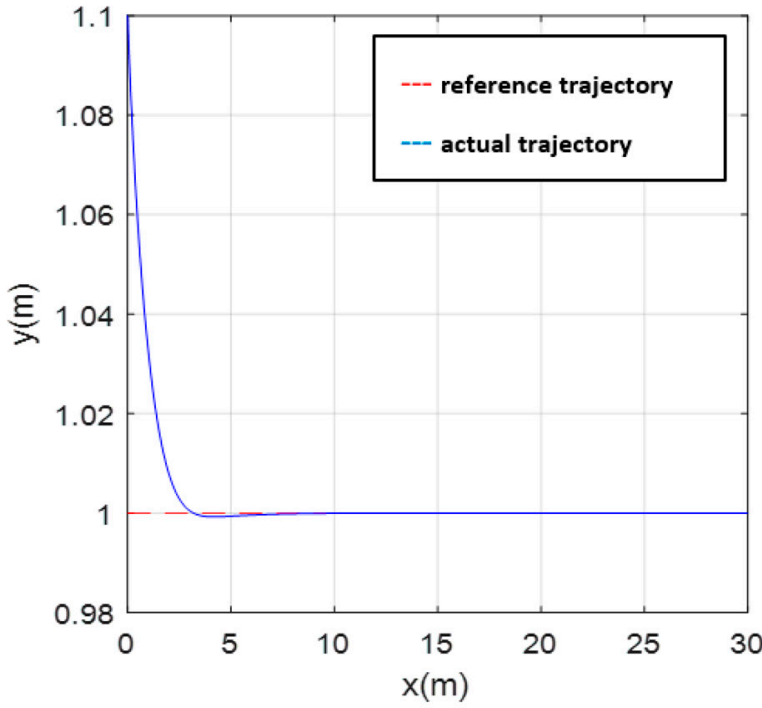

(b)

Figure 10. Laboratory results in tracking position of circle route (a) and line route (b) by our controller.
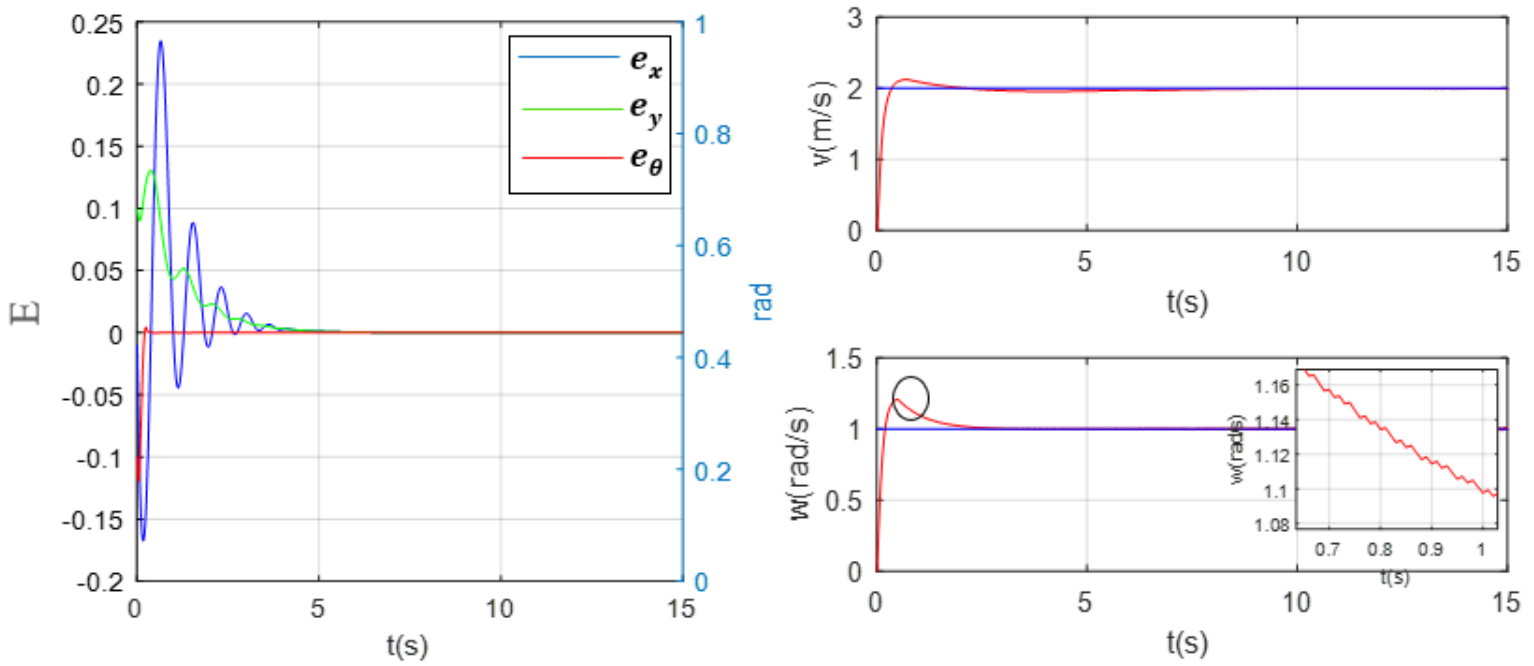

Figure 11. Laboratory results in tracking errors of circle route (a) and tracking velocities of line route (b) by our controller.

\section{Conclusions}

In this paper, a novel controller for MAC in the presence of uncertainties was introduced. In our work, the critical problems from real-world hardware are pointed out after handling in its distribution center or storehouse. Later, the potential solutions are studied to overcome these drawbacks. The contributions in this research could be summarized as following:

- Decoupling formation from kinematic-dynamic model of MAC is formed. Instead of solving the complicated system, it is advised to work with two second-order sub-systems.

- The globally asymptotic stability of whole system is validated in the sense of Lyapunov theory. Therefore, the design controller and adaptive rules are derived.

- $\quad$ Adapting with uncertain parameters, the proposed controller achieves excellent results in both the circular segment and linear segment. The competitive performance is also verified carefully to prove the effectiveness and correctness of our approach in agricultural warehouses. 
Author Contributions: Conceptualization, H.Q.T.N.; methodology, H.Q.T.N.; software, H.N.; validation, T.P.N.; formal analysis, H.N.; investigation, V.N.S.H.; writing-original draft preparation, H.Q.T.N.; writing一review and editing, H.Q.T.N.; visualization, H.N.; supervision, T.P.N. All authors have read and agreed to the published version of the manuscript.

Funding: This research received no external funding.

Acknowledgments: This research is funded by Vietnam National University HoChiMinh City (VNU-HCM) under grant number C2020-20-04. We acknowledge the support of time and facilities from Ho Chi Minh City University of Technology (HCMUT), VNU-HCM for this study.

Conflicts of Interest: The authors declare no conflict of interest.

\section{References}

1. Torii, T. Research in autonomous agriculture vehicles in Japan. Comput. Electron. Agric. 2000, 25, $133-153$. [CrossRef]

2. Reina, G.; Milella, A.; Galati, R. Terrain assessment for precision agriculture using vehicle dynamic modelling. Biosyst. Eng. 2017, 162, 124-139. [CrossRef]

3. Milosavljevic, S.; Bergman, F.; Rehn, B.; Carman, A.B. All-terrain vehicle use in agriculture: Exposure to whole body vibration and mechanical shock. Appl. Ergon. 2010, 41, 530-535. [CrossRef]

4. Primicerio, J.; Di Gennaro, S.F.; Fiorillo, E.; Genesio, L.; Lugato, E.; Matese, A.; Vaccari, F.P. A flexible unmanned aerial vehicle for precision agriculture. Precis. Agric. 2012, 13, 517-523. [CrossRef]

5. Carman, A.B.; Gillespie, S.; Jones, K.; Mackay, J.; Wallis, G.; Milosavljevic, S. All terrain vehicle loss of control events in agriculture: Contribution of pitch, roll and velocity. Ergon. 2010, 53, 18-29. [CrossRef]

6. Nielsen, K.; Andersen, P.; Pedersen, T.; Bak, T.; Nielsen, J.D. Control of an autonomous vehicle for registration of weed and crop in precision agriculture. In Proceedings of the International Conference on Control Applications, Glasgow, UK, 18-20 September 2002; Volume 2, pp. 909-914.

7. Herrera, D.; Tosetti, S.; Carelli, R.O. Dynamic Modeling and Identification of an Agriculture Autonomous Vehicle. IEEE Lat. Am. Trans. 2016, 14, 2631-2637. [CrossRef]

8. Hassan, M.U.; Ullah, M.; Iqbal, J. Towards autonomy in agriculture: Design and prototyping of a robotic vehicle with seed selector. In Proceedings of the 2016 2nd International Conference on Robotics and Artificial Intelligence (ICRAI), Rawalpindi, Pakistan, 1-2 November 2016; pp. 37-44.

9. Anokić, A.; Stanimirović, Z.; Davidović, T.; Stakic, D. Variable neighborhood search based approaches to a vehicle scheduling problem in agriculture. Int. Trans. Oper. Res. 2017, 27, 26-56. [CrossRef]

10. Quaglia, G.; Visconte, C.; Scimmi, L.S.; Melchiorre, M.; Cavallone, P.; Pastorelli, S. Design of the positioning mechanism of an unmanned ground vehicle for precision agriculture. In New Advances in Mechanism and Machine Science; Springer: Cham, Switzerland, 2019; pp. 3531-3540.

11. Jia, P.; Song, C.; Zhang, X. Control and simulation of adaptive global trajectory tracking for nonholonomic mobile robots with parameter uncertainties. In Proceedings of the 2012 International Symposium on Instrumentation \& Measurement, Sensor Network and Automation (IMSNA), Sanya, China, 25-28 August 2012; Volume 1, pp. 314-317.

12. Xin, L.; Wang, Q.; She, J.; Li, Y. Robust adaptive tracking control of wheeled mobile robot. Robot. Auton. Syst. 2016, 78, 36-48. [CrossRef]

13. Park, B.S.; Yoo, S.J.; Park, J.B.; Choi, Y.H. A Simple Adaptive Control Approach for Trajectory Tracking of Electrically Driven Nonholonomic Mobile Robots. IEEE Trans. Control. Syst. Technol. 2009, 18, 1199-1206. [CrossRef]

14. Haqshenas, M.A.; Fateh, M.M.; Ahmadi, S.M. Adaptive control of electrically-driven nonholonomic wheeled mobile robots: Taylor series-based approach with guaranteed asymptotic stability. Int. J. Adapt. Control. Signal Process. 2020, 34, 638-661. [CrossRef]

15. Pourboghrat, F.; Karlsson, M.P. Adaptive control of dynamic mobile robots with nonholonomic constraints. Comput. Electr. Eng. 2002, 28, 241-253. [CrossRef]

16. Boukens, M.; Boukabou, A.; Chadli, M. Robust adaptive neural network-based trajectory tracking control approach for nonholonomic electrically driven mobile robots. Robot. Auton. Syst. 2017, 92, 30-40. [CrossRef] 
17. Solea, R.; Filipescu, A.; Nunes, U. Sliding-mode control for trajectory-tracking of a wheeled mobile robot in presence of uncertainties. In Proceedings of the 2009 7th Asian Control Conference, Hong Kong, China, 27-29 August 2009; pp. 1701-1706.

18. Chen, H.; Zhang, B.; Zhao, T.; Wang, T.; Li, K. Finite-time tracking control for extended nonholonomic chained-form systems with parametric uncertainty and external disturbance. J. Vib. Control. 2016, 24, 100-109. [CrossRef]

19. Fierro, R.; Lewis, F.L. Control of a nonholomic mobile robot: Backstepping kinematics into dynamics. J. Robotic Syst. 1997, 14, 149-163. [CrossRef]

20. Ibari, B.; Benchikh, L.; Elhachimi, A.R.H.; Ahmed-Foitih, Z. Backstepping approach for autonomous mobile robot trajectory tracking. Indones. J. Electr. Eng. Comput. Sci. 2016, 2, 478-485.

21. Shakourzadeh, S.; Farrokhi, M. Fuzzy-backstepping control of quadruped robots. Intell. Serv. Robot. 2020, 13, 191-206. [CrossRef]

22. Ibari, B.; Benchikh, L.; Bouzgou, K.; Elhachemi, R.; Ahmed-Foitih, Z. Backstepping controller with force estimator applied for mobile robot. PRZEGLACD ELEKTROTECHNICZNY 2019, 1, 20-23. [CrossRef]

23. Fierro, R.; Lewis, F. Control of a nonholonomic mobile robot using neural networks. IEEE Trans. Neural Netw. 1998, 9, 589-600. [CrossRef]

24. Abdessemed, F.; Benmahammed, K.; Monacelli, E. A fuzzy-based reactive controller for a non-holonomic mobile robot. Robot. Auton. Syst. 2004, 47, 31-46. [CrossRef]

25. Das, T.; Kar, I. Design and implementation of an adaptive fuzzy logic-based controller for wheeled mobile robots. IEEE Trans. Control. Syst. Technol. 2006, 14, 501-510. [CrossRef]

26. Khalaji, A.K.; Moosavian, S.A.A. Robust Adaptive Controller for a Tractor-Trailer Mobile Robot. IEEE/ASME Trans. Mechatron. 2013, 19, 943-953. [CrossRef]

27. Seelinger, M.; Yoder, J.-D. Automatic visual guidance of a forklift engaging a pallet. Robot. Auton. Syst. 2006, 54, 1026-1038. [CrossRef]

28. Shen, Y.; Chu, B.; Liu, D.; Zhu, C. An Optimization of Steering System of Forklift Vehicle for Idle Performance. Math. Probl. Eng. 2015, 2015, 1-9. [CrossRef]

29. Xie, Y.; Zhang, X.; Meng, W.; Zheng, S.; Jiang, L.; Meng, J.; Wang, S. Coupled fractional-order sliding mode control and obstacle avoidance of a four-wheeled steerable mobile robot. ISA Trans. 2020, in press. [CrossRef]

30. Arab, A.; Mousavi, Y. Optimal Control of Wheeled Mobile Robots: From Simulation to Real World. In Proceedings of the 2020 American Control Conference (ACC), Denver, CO, USA, 1-3 July 2020; pp. 583-589.

31. Ushkalov, V.F.; Zhechev, M.M.; McKisic, A.D. Possibility of jamming and wedging in the three-piece trucks of a moving freight car. Veh. Syst. Dyn. 2007, 45, 61-76. [CrossRef]

32. Ngo, H.Q.T.; Nguyen, T.P.; Nguyen, H. An Innovative Hardware Bridging Between Education and Industry. In Proceedings of the 2019 14th International Conference on Computer Science \& Education (ICCSE), Toronto, ON, Canada, 19-21 August 2019; pp. 703-708.

33. Ngo, H.Q.T.; Phan, M.-H. Design of an Open Platform for Multi-Disciplinary Approach in Project-Based Learning of an EPICS Class. Electronics 2019, 8, 200. [CrossRef]

34. Zhai, J.-Y.; Song, Z. Adaptive sliding mode trajectory tracking control for wheeled mobile robots. Int. J. Control. 2018, 92, 2255-2262. [CrossRef]

Publisher's Note: MDPI stays neutral with regard to jurisdictional claims in published maps and institutional affiliations.

(C) 2020 by the authors. Licensee MDPI, Basel, Switzerland. This article is an open access article distributed under the terms and conditions of the Creative Commons Attribution (CC BY) license (http://creativecommons.org/licenses/by/4.0/). 